*Doutorando em Direito pela UNIMAR (Universidade de Marília). Mestre em Direito pela UNIMAR. Graduado em Direito pela ITE (Instituição Toledo de Ensino). Advogado. Controlador Interno da Câmara Municipal de Jaú/SP. E-mail: du.devides@ gmail.com.

aria.fernandes@unipe.edu.br

**Doutor em Direitos Humanos e Desenvolvimento pela Universidade Pablo de Olavide, de Sevilha, Espanha (2009). Professor permanente do Programa de Mestrado e Doutorado em Direito da UNIMAR (Universidade de Marília). Procurador da República do Ministério Público Federal em Marília/SP. E-mail: jeff.bojador@ gmail.com;

***Doutora em Educação pela Universidade Estadual Paulista Júlio de Mesquita Filho (2001). Mestra em Educação pela Universidade Estadual Paulista Júlio de Mesquita Filho (1996). Graduada em Ciências Sociais pela Universidade Estadual Paulista Júlio de Mesquita Filho (1989). Professora permanente do Programa de Mestrado e Doutorado em Direito da UNIMAR (Universidade de Marília). E-mail: walkiriamf@ terra.com.br

\section{O Desafio do Projeto da nova Lei De Licitações Com Vistas À Democracia Participativa: O Diálogo COMPETITIVo}

THE CHALLENGE OF THE NEW BIDDING LAW BILL IN LIGHT OF PARTICIPATORY DEMOCRACY: THE COMPETITIVE DIALOGUE

\section{José Eduardo Costa Devides* Jefferson Aparecido Dias** Walkiria Martinez Heinrich Ferrer $* * *$}

Como citar: DEVIDES, José Eduardo Costa; DIAS, Jefferson Aparecido; FERRER, Walkiria Martinez Heinrich. O desafio do projeto da nova lei de licitações com vistas à democracia participativa: o diálogo competitivo. Scientia Iuris, Londrina, v. 25, n. 1, p. 128-143, mar. 2021. DOI: $10.5433 / 21788189.2021 \mathrm{v} 25 \mathrm{n} 1 \mathrm{p} 128$. ISSN: $2178-8189$.

Resumo: O objetivo do presente artigo é analisar se o diálogo competitivo, nova modalidade de licitação prevista no Projeto de Lei $\mathrm{n}^{\circ} 1.292 / 95$, se identifica como instrumento de democracia participativa. Inicialmente serão apresentadas as teorias das democracias (representativa, participativa e deliberativa), sustentando-se a importância da contínua aproximação entre o povo e o seu governo. Em seguida, serão analisadas as leis que tratam do procedimento licitatório e as propostas para a sua alteração, com a inclusão do diálogo competitivo. Na sequência, serão apresentados os desafios que deverão ser enfrentados pelo diálogo competitivo para que ele se concretize como instrumento de participação democrática, inclusive quanto à necessidade de ampliação da possibilidade de participação popular em seus debates, a fim de que efetivamente atinja os seus objetivos. $\mathrm{O}$ método de pesquisa adotado foi o dedutivo, tendo a abordagem sido desenvolvida a partir de investigações de cunho qualitativo e pesquisa bibliográfica.

Palavras-chave: Diálogo competitivo. Licitação. Teorias das democracias. Democracia Participativa.

Abstract: This paper's objective is to analyze whether competitive dialogue, a new type of public bidding provided for in Bill $\mathrm{n}^{\circ} 1,292 / 95$, is itself an instrument of a participatory democracy. Initially, this study explores the three theories of democracy (representative, participatory and deliberative), 
whilst trying to analyze the relationship between the people and their government. Sequentially, this paper investigates laws, which established its bidding procedure, and proposals for its reform. Sequentially, this research considers the obstacles facing competitive dialogue as a tool for democratic participation, significantly expanding the possibility of popular participation in debates. This paper utilizes deductive reasoning with both qualitative investigations and bibliographic research.

Keywords: Competitive dialogue. Bidding. Democracy theories. Participatory Democracy. 


\section{INTRODUÇÃO}

Desde tempos remotos, os meios midiáticos vêm noticiando atos de corrupção envolvendo agentes públicos e licitantes, que camuflam procedimentos licitatórios com a finalidade de obterem vantagem financeira indevida, trazendo como consequência o enriquecimento ilícito, das duas partes, assim como prejuízo aos cofres públicos.

O problema do presente trabalho é pautado na descrença da população com os governantes e a democracia, e a necessidade da criação de medidas (como o envolvimento com o orçamento participativo, o acesso aos portais de transparência e o comparecimento nas sessões públicas licitatórias) que visem remediar tal situação.

A justificativa da pesquisa é baseada na importância da participação popular nas questões relativas ao interesse público, haja vista que obriga os governantes a cumprir suas funções institucionais, forçando-os a dar destinação correta ao dinheiro público. Salienta-se que a destinação correta do erário resulta em benefícios diversos à população, como os relativos à saúde, à educação, ao trabalho, à moradia, ao meio ambiente equilibrado, dentre outros.

Ademais, o objetivo do presente trabalho é verificar se o diálogo competitivo é uma forma de efetivação da democracia participativa. Noutros termos, o diálogo competitivo seria capaz de remediar o descrédito com o modelo democrático e a desconfiança nos administradores públicos?

Com efeito, a pesquisa foi elaborada em três capítulos. O primeiro aborda as teorias das democracias e a necessidade (contínua) da aproximação entre povo e governo. O segundo discorre sobre o procedimento licitatório brasileiro, o projeto da nova lei de licitações e a nova modalidade licitatória, o diálogo competitivo. O último capítulo cuida dos desafios do diálogo competitivo frente aos atuais clamores sociais, questionando sobre este se tratar de mecanismo que objetiva a efetivação da democracia participativa.

Assim, a presente pesquisa será apresentada por intermédio do método dedutivo, a partir de investigações de cunho qualitativo, com ampla pesquisa bibliográfica, no intuito de se solucionar o problema proposto.

\section{AS TEORIAS DAS DEMOCRACIAS E A NECESSIDADE (CONTÍNUA) DA APROXIMAÇÃO ENTRE POVO E GOVERNO}

Em meio à sociedade pós-moderna, fase marcada pela globalização ${ }^{1}$ e pelo avanço dos meios de comunicação, a democracia passou por uma evolução conceitual no tocante à forma

\footnotetext{
1 A globalização é política, tecnológica e cultural, tanto quanto econômica, e tem algo a ver com a tese de que agora vive-se num único mundo, sendo influenciada pelo desenvolvimento nos sistemas de comunicação que remontam apenas ao final da década de 1960 (GIDDENS, 2003, p. 19-21).
} 
de participação do cidadão, descrevendo outras condutas além do voto, como a participação e o debate nas questões de interesse público. Assim, este capítulo cuidará de discorrer acerca das democracias representativa, participativa e deliberativa.

Democracia é a forma de governo na qual o povo elege os seus representantes por intermédio do voto, tendo estes a obrigatoriedade de gerir a máquina pública de forma proba e eficiente. Assim, trata-se de governo do povo, pelo povo e para o povo. Segundo José Afonso da Silva

Governo do povo significa que este é fonte e titular do poder (todo poder emana do povo), de conformidade com o princípio da soberania popular que é, pelo visto, o princípio fundamental de todo regime democrático. Governo pelo povo quer dizer governo que se fundamenta na vontade popular, que se apoia no consentimento popular; governo democrático é o que se baseia na adesão livre e voluntária do povo à autoridade, como base da legitimidade do exercício do poder, que se efetiva pela técnica da representação polític: 1 (o poder é exercido em nome do povo). Governo para o povo há de ser aquele que procure liberar o homem de toda imposição autoritária e garantir o máximo de segurança e bemestar (SILVA, 2014, p. 137, grifos do autor).

Com efeito, a democracia representativa (que também é denominada democracia indireta) é aquela na qual os indivíduos, que são a fonte principal do poder, não possuem condições de coordenar os negócios do Estado de forma direta, em face da sua extensão territorial, da densidade demográfica e da complexidade dos problemas sociais, e outorgam as funções de governo aos seus representantes, que elegem periodicamente (SILVA, 2014, p. 138).

Por conseguinte, a democracia participativa é aquela na qual existe a participação direta do povo nas funções do governo, que também é classificada como democracia semidireta (SILVA, 2014, p. 138). Para a efetiva participação, todavia, é necessário que a sociedade tome conhecimento de alguns assuntos atinentes à funcionalidade da administração pública. Por certo, a atuação ativa e responsável da sociedade implica em pessoas informadas "e dotadas de condições de expressar livremente suas opiniões sobre o conteúdo das decisões políticas, o que ultrapassa a visão liberal e negativa de caráter absenteísta, para considerá-las liberdades positivas que podem ser exigidas do Estado." (RUE; SILVA, 2014). Ademais, na "democracia contemporânea, o que importa é a participação da elite minoritária, e a não participação do homem comum, apático, com pouco senso de eficácia política é vista como a principal salvaguarda contra a instabilidade." (PATEMAN, 1992, p. 139). Um ambiente participativo cria, no indivíduo, o sentimento de eficácia das medidas adotadas pelo governo, fazendo diminuir a tendência de atitudes não-democráticas (PATEMAN, 1992, p. 139).

Segundo Hannah Arendt, deve haver a recuperação do espaço público para a efetivação do agir em conjunto. Trata-se do espaço "cuja própria existência depende diretamente de que os homens permaneçam juntos e dispostos a agir e falar entre si, desaparecendo quando quiser que eles se vejam isolados uns dos outros." (ARENDT, 1998, p. 211). O agir em conjunto proporciona 
a inovação de soluções em benefício da democracia:

A Filosofia Política de Arendt representa uma tentativa de encarar o acontecimento e agir, afrontando a contingência humana, com a vontade de superar os limites. Trata-se de preservar a confiança na capacidade que as pessoas têm de julgar, de inventar soluções novas e de agir em conjunto, visando à preservação do mundo comum. Esse Amor Mundi se manifesta como cidadania e se efetiva como amizade política, compreendida como atividade de criação e de experimentação de novas formas de sociabilidade e solidariedade. A Democracia exige dos cidadãos o exercício comum de suas liberdades comunicativas, extraindo do Direito a sua força integradora de fontes da solidariedade social (FLENIK, 2018, p. 301).

Assim, a "ampliação das oportunidades de participação geraria um salto na qualidade da representação" (MIGUEL, 2017, p. 89), na medida em que pessoas esclarecidas quanto à forma de operacionalização da máquina pública obrigariam os governantes a atuarem de forma mais diligente. "O poder dos cidadãos somente se manifesta quando eles de fato se reúnem para falar e agir, no que tange aos interesses do mundo da vida que desejam para si, com reflexos na tomada de decisões políticas pelos agentes públicos" (FLENIK, 2018, p. 301). E a consequência da atuação diligente resulta em efetividade da aplicação do erário para a realização do bem comum.

No que tange à última espécie de democracia, a deliberativa, Bohman estabelece que se trata de "qualquer perspectiva entre um conjunto de perspectivas de acordo com as quais a deliberação pública entre os cidadãos livres e iguais constitui o núcleo da tomada legítima de decisões políticas e de autogoverno" (BOHMAN, 2016, p. 107, tradução nossa).

Saliente-se que a democracia deliberativa possui as seguintes características:

[...] fóruns públicos abertos a argumentos contrários e a novos dados e informações; grupos moldados para a proposição de políticas públicas, com abertura para mudança de opinião; experiências com cidadãos selecionados por amostragem representativa da população e júris de cidadãos, pesquisa deliberativa, assembléias de cidadãos, dia deliberativo, fóruns de discussão via internet (e-democracy) (LACERDA; MONTEIRO; MOURA, 2015, p. 183).

Para Bohman, ademais, as teorias deliberativas enfatizam o próprio processo de deliberação, haja vista que conduzem à ênfase nos aspectos voltados à epistemologia, à moral e à justificação pública; preocupam-se com problemas de institucionalização, ao invés da democracia direta; traçam um comparativo de cenários e procedimentos de deliberação (obstáculos empíricos) (BOHMAN, 2016).

Ainda, segundo esta corrente democrática, embora o foco esteja direcionado aos fóruns dos Estados para deliberação pública, ela mantém opiniões relacionadas com o cosmopolitismo. De 
fato, "recomendações deliberativo-democráticas são especialmente bem talhadas para instituições transnacionais como o Parlamento Europeu ou fóruns patrocinados pela ONU, tais como suas conferências sobre desenvolvimento e meio ambiente." (CUNNINGHAM, 2009, p. 246).

Todavia, à luz da visão neomaquiaveliana, as duas últimas espécies democráticas (participativa e deliberativa) não seriam colocadas em efetividade pela simples vontade dos governantes. Isso porque, segundo esta classe de doutrinadores, a sociedade está dividida em uma maioria governada e uma minoria dominante, na qual a fundação da ordem social repousa sobre a organização interna da classe dominante (BLACHA, 2016), que não possui interesse em atrair a população para participar das decisões que envolvam a coisa pública. Pelo contrário, o desejo da minoria dominante é que grande massa se mantenha afastada e alienada dos assuntos de interesse público.

Realizando uma análise mais acurada "da realidade brasileira, qualquer sociólogo, politólogo ou jurista - que faça valer essa qualificação, não poderá se distanciar da conclusão de que a esfera pública sempre esteve alheia às camadas mais pobres da população." (MACHADO; TOMAZ, 2018, p. 458), dificultando, no mais das vezes, a participação das grandes massas. Sobre este tema, discursa Carmén Lúcia Antunes Rocha:

[...] o poder no Brasil sempre se estruturou à margem do cidadão. Na verdade, não é que o povo seja marginal ao poder estatal brasileiro. Esse é que nunca quis "se misturar" com o povo e faz a sua própria história à margem daquele. Planos, projetos, órgãos estatais, nada funciona em termos de direitos fundamentais enquanto a adesão do povo ao projeto político cidadão, respeitador e respeitante aos direitos fundamentais dos brasileiros, de todos os brasileiros. O poder público no Brasil tem sido, tradicional e infelizmente, muito pouco público, muito pouco do povo. Ele é exercido não pelo povo ou em seu nome e interesse, mas por uns poucos grupos que o dominam desde os primórdios, em seu nome e em seu próprio e único interesse (ROCHA, 1997, p. 85).

Destarte, é necessária a união dos indivíduos para que não ocorra o distanciamento dos administradores. Para tanto, a aproximação e cientificação dos assuntos de interesse público, como o acesso aos portais de transparências, o comparecimento aos orçamentos participativos, o envolvimento com sessões públicas de licitação, verbi gratia, são mecanismos que visam garantir que os agentes políticos realizem suas funções de acordo com os fins propostos. A aproximação é a melhor maneira de obrigar a minoria governante a zelar pelo erário e a executar suas funções institucionais.

\section{O PROCEDIMENTO LICITATÓRIO BRASILEIRO, O PROJETO DA NOVA} LEI DE LICITAÇÕES E A NOVA MODALIDADE LICITATÓRIA: O DIÁLOGO 


\section{COMPETITIVO}

A Constituição da República previu, no art. 37, inciso XXI, a obrigatoriedade de a Administração Pública realizar licitação para aquisição de bens e contratação de obras e serviços:

Art. 37. A administração pública direta e indireta de qualquer dos Poderes da União, dos Estados, do Distrito Federal e dos Municípios obedecerá aos princípios de legalidade, impessoalidade, moralidade, publicidade e eficiência e, também, ao seguinte:

$[\ldots]$

XXI - ressalvados os casos especificados na legislação, as obras, serviços, compras e alienações serão contratados mediante processo de licitação pública que assegure igualdade de condições a todos os concorrentes, com cláusulas que estabeleçam obrigações de pagamento, mantidas as condições efetivas da proposta, nos termos da lei, o qual somente permitirá as exigências de qualificação técnica e econômica indispensáveis à garantia do cumprimento das obrigações (BRASIL, 1988).

Realizando uma interpretação conjunta ente o caput e o inciso do dispositivo, nota-se que o administrador público deverá realizar a licitação sempre pautada nos princípios ${ }^{2}$ da legalidade, impessoalidade, moralidade, publicidade e eficiência. Isto significa que:

a) as contratações devem atender às regras previstas na legislação, notadamente àquelas definidas na Lei $n^{\circ}$ 8.666/93 (Lei Geral de Licitações) e na Lei no 10.520/2002 (Lei do Pregão Presencial), em obediência ao princípio da legalidade;

b) é vedada a conduta consistente em garantir tratamentos discriminatórios em relação a algum agente econômico que esteja no mesmo patamar de igualdade em relação aos demais ${ }^{3}$. Ou seja, ao Estado é proibido garantir benefícios, a seu bel-prazer, a determinado licitante;

c) todo o servidor público que participar da licitação, seja na fase interna ou externa, "como ser humano dotado da capacidade de atuar, deve, necessariamente, distinguir o Bem do Mal, o honesto do desonesto. E, ao atuar, não poderá desprezar o elemento ético de sua conduta" (MEIRELES, 2009, p. 90). Assim, acima de tudo, o servidor deverá atender à lei ética e não somente à lei jurídica, tendo em vista que nem tudo que é legal é honesto;

d) a publicidade é medida de rigor na administração pública, para que a transparência e o direito à informação da população sejam efetivados. "A licitação não pode ser sigilosa, sendo públicos e acessíveis ao público os atos de seus procedimentos. Impõe-se, contudo, o sigilo do conteúdo das propostas até a respectiva abertura" (BRAZ, 2009, p. 330). A publicação dos avisos

2 Salienta-se que a licitação ainda deverá respeitar outros princípios do Direito Administrativo: o da supremacia e da indisponibilidade do interesse público, o da igualdade, o da motivação, o da finalidade, o da probidade administrativa, o da vinculação ao instrumento convocatório, o do julgamento objetivo, entre outros.

3 Existem situações previstas na legislação em que é possível o tratamento discriminatório, como aqueles elencados na Lei $\mathrm{n}^{\mathrm{o}} 123 / 2016$, atinentes ao tratamento diferenciado concedido às microempresas e às empresas de pequeno porte. 
de edital, dos próprios editais e extratos de contrato são alguns exemplos que traduzem o princípio da publicidade;

e) o procedimento licitatório deve ser eficiente, o que significa dizer que deve "acontecer com racionalidade, o que implica medir os custos que a satisfação das necessidades públicas importa em relação ao grau de utilidade alcançado. [...]. Rege-se, pois, pela regra da consecução do maior benefício com o menor custo possível" (SILVA, 2014, p. 680).

Atualmente, as licitações públicas são regulamentadas, primordialmente, por três leis: Lei n. ${ }^{\circ}$ 8.666/93 (Lei Geral das Licitações Públicas); Lei n. ${ }^{\circ}$ 10.520/02 (Lei do Pregão) e Lei n. ${ }^{\circ}$ 12.462/11 (que trata do Regime Diferenciado de Contratações e traz outras disposições).

Ocorre que, em 2013, o Projeto da Nova Lei de Licitações (n. ${ }^{\circ}$ 559/2013) foi protocolado no Senado Federal, por iniciativa da Comissão de Modernização da Lei de Licitações e Contratos. Segundo o relatório desta Comissão, a reforma da legislação atual sobre licitações teriam alguns propósitos, quais sejam: a) a união das Leis n. 8.666/93 (Lei de Licitações), 10.520/02 (Lei do Pregão) e 12.462/11, em um único diploma legal, que também seria acrescido de inovações; b) o fim do formalismo em excesso, sendo conferida maior celeridade aos procedimentos, a fim de se conseguir melhor qualidade nas compras; c) a garantia do tratamento isonômico entre os participantes; e d) o incentivo a inovação tecnológica e a promoção do desenvolvimento sustentável no território nacional.

Interessante notar que, além dos princípios elencados na Lei n. ${ }^{\circ} 8.666 / 93$, o projeto ainda elencou os seguintes: eficácia, motivação, segurança jurídica, razoabilidade, competitividade, proporcionalidade, celeridade, economicidade e sustentabilidade. Com aprovação no Senado, em 2017 o projeto da nova lei licitatória foi encaminhado à Câmara dos Deputados (que recebeu o número 6.814/17).

Saliente-se que em junho de 2019 houve a aprovação do texto base da Lei n. ${ }^{\circ}$ 1.292/1995, que consolidou as informações do Projeto de Lei n. ${ }^{\circ} 6.814 / 17$, e de outros 239 processos apensados, sobre o tema. Dentre as novidades trazidas pelo projeto (e que já havia previsão no PLS n. ${ }^{\circ}$ 559/2013), encontra-se o diálogo competitivo ${ }^{4}$, nova modalidade de licitação:

Art. 31. O modo de diálogo competitivo é restrito a contratações em que a Administração:

I - vise a contratar objeto que envolva as seguintes condições:

a) inovação tecnológica ou técnica;

b) o órgão ou entidade não possa ter suas necessidades satisfeitas sem a adaptação de soluções disponíveis no mercado; e

c) especificações técnicas não possam ser definidas com precisão suficiente pela Administração;

II - verifique a necessidade de definir e identificar os meios e as alternativas que possam vir a satisfazer suas necessidades, com destaque para os seguintes aspectos:

a) a solução técnica mais adequada;

b) os requisitos técnicos aptos a concretizar a solução já definida;

4 Procedimento que foi encampado da Directiva 2004/18, do Parlamento Europeu. 
c) a estrutura jurídica ou financeira do contrato;

III - considere que os modos de disputa aberto e fechado não permitem apreciação adequada das variações entre propostas.

$\S 1^{\circ} \mathrm{Na}$ hipótese de diálogo competitivo, será observado o seguinte:

I - quando da divulgação do edital em sítio eletrônico oficial, a Administração apresentará suas necessidades e as exigências já definidas, estabelecendo prazo mínimo de 25 (vinte e cinco) dias úteis para manifestação de interesse de participação na licitação;

II - os critérios empregados para pré-seleção dos licitantes deverão ser previstos em edital e serão admitidos todos os interessados que preencherem os requisitos objetivos estabelecidos;

III - é vedada a divulgação de informações de modo discriminatório que possa implicar vantagem para algum licitante;

IV -a Administração não poderá revelar a outros licitantes as soluções propostas ou as informações sigilosas comunicadas por um licitante sem o seu consentimento; $\mathrm{V}$ - a fase de diálogo poderá ser mantida até que a Administração, em decisão fundamentada, identifique a solução ou as soluções que atendam às suas necessidades;

$\mathrm{VI}$ - as reuniões com os licitantes pré-selecionados serão registradas em ata e gravadas mediante utilização de recursos tecnológicos de áudio e vídeo;

VII - o edital poderá prever a realização de fases sucessivas, caso em que cada fase poderá restringir soluções ou as propostas a serem discutidas;

VIII - ao declarar que o diálogo foi concluído, a Administração deverá juntar aos autos do processo licitatório os registros e as gravações da fase de diálogo e iniciará a fase competitiva com a divulgação de edital contendo a especificação da solução que atenda às suas necessidades e os critérios objetivos a serem utilizados para seleção da proposta mais vantajosa, abrindo prazo, não inferior a 60 (sessenta) dias úteis, para todos os licitantes apresentarem suas propostas, que deverão conter todos os elementos necessários para a realização do projeto; IX - A Administração poderá solicitar esclarecimentos ou ajustes às propostas apresentadas, desde que não impliquem discriminação ou distorçam a concorrência entre as propostas;

X - a Administração definirá a proposta vencedora de acordo com critérios a serem divulgados no início da fase competitiva, assegurando o resultado da contratação mais vantajosa;

XI - o diálogo competitivo será conduzido por comissão de contratação composta de pelo menos 3 (três) servidores efetivos ou empregados públicos pertencentes aos quadros permanentes da Administração, admitindo-se a contratação de profissionais para assessoramento técnico da comissão;

XII - órgão de controle poderá acompanhar e monitorar os diálogos competitivos, opinando, no prazo máximo de 40 (quarenta) dias úteis, sobe a legalidade, legitimidade e economicidade da licitação, antes da celebração do contrato respectivo.

$\S 2^{\circ}$ Os profissionais contratados para os fins do inciso XI do $\S 1^{\circ}$ assinarão termo de confidencialidade e abster-se-ão de atividades que possam configurar conflito de interesses (BRASIL, 1995).

De forma resumida, o diálogo competitivo é a modalidade licitatória na quala Administração pública um instrumento convocatório com a finalidade de atrair agentes econômicos que possam 
lhe auxiliar na elaboração de edital futuro, de objeto complexo, para que as suas necessidades sejam definidas e supridas com precisão. Essa ajuda, pelos agentes econômicos, pode ocorrer desde a formação do objeto do edital (quando for referente, por exemplo, a inovação tecnológica), até a estruturação jurídica ou financeira do contrato. Assim, a ideia contida no núcleo do diálogo é que o Poder Público conte com "a colaboração dos operadores econômicos para a definição do objeto do qual o Estado necessita e, em razão da sua complexidade, não tem condições de definir sozinho o objeto da contratação." (OLIVEIRA, 2018, p. 10).

Vencida a fase do diálogo (que poderá ser prolongada, até que a Administração identifique a solução ou as soluções que atendam às suas necessidades) haverá a publicação do edital que objetivará a contratação do objeto já delimitado pelo Poder Público, sendo que a comissão licitante poderá incluir profissionais para assessoramento técnico, mediante contratação.

Em um plano teórico, a nova modalidade de licitação demonstra que tem o condão de garantir benefícios no momento da contratação, à medida que a definição precisa do objeto contribui para:

a) que sejam evitados erros técnicos durante a fase licitatória, atrasando os planos da Administração e comprometendo a necessidade (pública) do objeto a ser contratado (em prol da eficiência);

b) que não ocorram falhas na execução contratual, que muitas vezes obrigam o Poder Público a paralisar obras e recontratar o mesmo serviço, posteriormente, culminando com maior gasto de dinheiro para a recuperação das mesmas. Essa forma de planejamento, sem dúvida, contribui para a otimização dos gastos (em benefício da economicidade e da eficiência);

c) o tratamento igualitário entre todos os interessados. Pelo que define o art. 31 do aludido PL, o diálogo competitivo não permitirá tratamento discriminatório entre quaisquer interessados, tendo em vista que o Poder Público não imporá barreiras para que os agentes econômicos possam lhe auxiliar a elaborar o objeto da licitação, tampouco para que os licitantes possam participar da licitação propriamente dita (em obediência ao princípio da impessoalidade). Sobre este aspecto, ademais, há de se reconhecer que o diálogo competitivo visa à garantia da livre concorrência, prevista no inciso IV, do art. 170 da Constituição Federal ${ }^{5}$. Consabido, aludido princípio é um desdobramento da livre iniciativa, sendo conceituado como a "abertura jurídica concedida aos particulares para competirem entre si, em segmento lícito, objetivando o êxito econômico pelas leis de mercado e a contribuição para o desenvolvimento nacional e a justiça social" (TAVARES, 2011, p. 256). Assim, a livre concorrência objetiva que os agentes econômicos disputem o diálogo competitivo em pé de igualdade;

5 Art. 170. A ordem econômica, fundada na valorização do trabalho humano e na livre iniciativa, tem por fim assegurar a todos existência digna, conforme os ditames da justiça social, observados os seguintes princípios: [...] IV - livre concorrência; (BRASIL, 1988). 
d) a moralidade do procedimento, haja vista que determina que a comissão deva ser formada por pelo menos 3 (três) servidores efetivos, sendo admitida a contratação de profissionais para assessoramento técnico da comissão;

e) a publicidade do procedimento, tendo em vista que o art. 52 do PL n. ${ }^{\circ}$ 1.292/95 dispõe que a publicidade do edital será realizada mediante a "divulgação e manutenção do inteiro teor do edital e seus anexos à disposição do público em sítio eletrônico oficial" (art. 52, caput) (BRASIL, 1995), sendo obrigatória a disponibilização do instrumento convocatório e seus anexos, ainda, no Portal Nacional de Contratações Públicas (PNCP).

Destarte, verifica-se que o diálogo competitivo, em um plano teórico, trará grande contribuição para o sistema licitatório brasileiro, notadamente para a delimitação do objeto da licitação e o consequente proveito na contratação realizada.

\section{OS DESAFIOS DO DIÁLOGO COMPETITIVO FRENTE AOS ATUAIS CLAMORES SOCIAIS: TRATA-SE DE MECANISMO QUE VISA À EFETIVAÇÃO DA DEMOCRACIA PARTICIPATIVA?}

Em tempos recentes, os meios midiáticos noticiaram que agentes públicos e licitantes camuflaram procedimentos licitatórios com a finalidade de obterem vantagem financeira indevida, trazendo como consequência o enriquecimento ilícito, das duas partes, assim como o prejuízo aos cofres públicos. Saliente-se que o descrédito histórico da população com os governantes foi somado à desesperança da população com relação ao regime democrático, o que resultou no direcionamento das seguintes situações: o afastamento do indivíduo com relação a informações de cunho político ou, ainda quando próximo ao assunto, as discussões cotidianas guarneciam de conteúdo meramente superficial.

Com efeito, a fraude em contratações, a descrença na democracia, e a falta de participação dos indivíduos nas questões de interesse público desafiam os fins previstos na legislação e atrapalham o desenvolvimento nacional.

De acordo com o filósofo e economista Amartya Sen, desenvolvimento é um processo de expansão das liberdades das pessoas e remoção de suas principais fontes de privação, que são a "pobreza e tirania, carência de oportunidades econômicas e destituição social sistemática, negligência dos serviços públicos e intolerância ou interferência excessiva de Estados repressivos." (SEN, 2010, p. 16-17). Nesse sentido, a liberdade política do indivíduo representa uma das espécies que devem ser exteriorizadas, pois

[...] essa liberdade envolve o direito de as pessoas escolherem seus próprios governantes, a possibilidade de fiscalizarem e criticarem os administradores públicos, assim como de terem liberdades de expressão política, de escolherem diferentes partidos políticos e de obterem uma imprensa sem censura (DEVIDES, 
DIAS, 2018, p. 218).

Noutros termos, a expansão da liberdade política conduz ao desenvolvimento ${ }^{6}$ do Estado.

Caso o Projeto de Lei n. ${ }^{\circ}$ 1.292/95 venha a ser promulgado da forma como redigido, o diálogo competitivo (art. 31) seria um instituto capaz de remediar a desesperança com a democracia? Estar-se-ia, ademais, diante de um mecanismo de efetivação da democracia participativa?

Recapitulando, a democracia participativa é aquela que permite a participação direta da população nos assuntos de interesse público, a exemplo do que ocorre com o orçamento participativo. Noutros termos, trata-se da reunião de pessoas que buscam a cientificação de assuntos que visam beneficiar a coletividade momento da qual ocorre o debate de ideias e a emissão de eventuais sugestões. A participação, aliás, tem por finalidade educar e informar o cidadão, "ao mesmo tempo em que amplia o seu senso de eficácia política." (LACERDA; MONTEIRO; MOURA, 2015, p. 182).

É hialino que o diálogo competitivo possui uma característica peculiar em relação a qualquer outra modalidade de licitação já existente no Brasil (inclusive em relação as demais presentes no PL n. ${ }^{\circ}$ 1.292/95). Essa característica se refere ao debate de ideais - que engloba exposição das necessidades do Poder Público e as sugestões que serão dadas pelos agentes econômicos - quando da convocação dos operadores econômicos, no intuito de que estes possam contribuir para que a Administração Pública construa o objeto da licitação de forma escorreita, sem deslizes, evitando dissabores futuros que violem princípios legais e constitucionais (notadamente, os atinentes à economicidade, moralidade, impessoalidade, publicidade e eficiência).

Constata-se que a convocação de licitantes para o debate de ideias, a princípio, reveste-se de uma forma de aplicação da democracia participativa, pois cada agente econômico, enquanto cidadão, está participando da vida pública. Contudo, uma ponderação deve ser feita: o agente que se envolver em um eventual diálogo com o Poder Público estará exercendo sua condição de representante de empresa, defendendo os interesses desta. Caso não existisse a representação, será que o licitante se dirigiria até a sessão pública e debateria ideias para ajudar a Administração a realizar a contratação mais vantajosa?

Aliás, à luz da essência da democracia participativa há de ser realizada uma crítica sobre o procedimento do diálogo competitivo. Além de prever a possibilidade da comissão ser

6 No tocante ao tema desenvolvimento, a primeira utilização do termo foi constatada no ano de 1967, na encíclica Populorum Progression, de Paulo VI. De acordo com a referida encíclica, o Estado teria o dever de garantir as providências essenciais para o progresso dos povos, por intermédio de ações voltadas "ao desenvolvimento integral do homem e para o desenvolvimento solidário da humanidade" (PAULO VI, 1967). Posteriormente, em 1986 a Resolução n. ${ }^{\circ}$ 41/128 da Assembleia Geral das Nações Unidas (a denominada Declaração sobre Direito ao Desenvolvimento), disciplinou, dentre outras disposições que os Estados deverão garantir o pleno exercício e o fortalecimento progressivo do direito ao desenvolvimento, incluindo a formulação, a adoção e a implementação de políticas, medidas legislativas e outras, em níveis nacional e internacional (ORGANIZAÇÃO DAS NAÇÕES UNIDAS, 1986). Dito isso, ainda que em matéria de licitações e contratos administrativos, é dever do Estado implementar medidas que tenha por fim o desenvolvimento nacional. Assim, esse é o papel que se espera da Administração Pública quando da execução da modalidade licitatória diálogo competitivo, haja vista os benefícios que esta espécie proporcionará à coletividade em que já foram elencados no capítulo anterior. 
composta por profissionais para assessoramento técnico (art. 31, inciso XI, do PL n. ${ }^{\circ}$ 1.292/95) condição que só se consumaria mediante a contratação dos mesmos - o projeto de lei poderia ter previsto a possibilidade de qualquer um do povo participar do diálogo, desde que, evidentemente, comprove as condições técnicas para tal encargo, de acordo com a especificação técnica exigida no instrumento convocatório (como a participação de pessoas com formação em tecnologia da informação e pós-graduação na área a ser abrangida pelo objeto da licitação, em certames que envolvessem a contratação de serviços específicos de tecnologia da informação).

Dessa forma, seria criada uma possibilidade para a participação de membros da sociedade, que teriam interesses diversos dos representantes de empresas ou de profissionais técnicos contratados para serem membros de comissão de licitação - que, evidentemente, participariam do diálogo mediante remuneração, seja dos patrões (no primeiro caso), seja do da própria Administração (no segundo caso) - sendo colocado em prática o efetivo exercício da democracia.

Destarte, verificou-se neste capítulo que, embora o diálogo competitivo preveja a possibilidade da participação de agentes econômicos e profissionais técnicos para debate sobre o aperfeiçoamento de determinado objeto que o Poder Público deseja contratar, tais participações apenas se concretizam em razão da remuneração que recebem em razão de suas obrigações. E (uma das formas) para que os clamores atuais da sociedade possam ser remediados - notadamente em relação à descrença na democracia - existe a necessidade de a Administração Pública fomentar a participação dos cidadãos em assuntos de interesse público. Para tanto, em se tratando de diálogo competitivo, seria ideal que o PL n. ${ }^{\circ}$ 1.292/95 passasse a permitir a participação de qualquer pessoa do povo neste tipo de debate, desde que ela comprove aptidão técnica condizente com o objeto da licitação.

\section{CONCLUSÕES}

Esta pesquisa objetivou analisar se a nova modalidade de licitação, prevista no Projeto de Lei n. ${ }^{\circ}$ 1.292/95 (da Câmara dos Deputados) - o diálogo competitivo, possui o condão de dar aplicabilidade à democracia participativa, para que a descrença social relativa aos governantes e à própria democracia possa ser mitigada/eliminada.

Para tanto, inicialmente, foram conceituadas as democracias representativa, participativa e deliberativa, tendo sido concluído que há a necessidade da união dos indivíduos para que não ocorra o distanciamento dos administradores (como, por exemplo, o acesso aos portais de transparências, o comparecimento aos orçamentos participativos, o envolvimento com sessões públicas de licitação), pois essa seria uma forma de obrigar o governante a zelar pelo erário e a executar suas funções institucionais.

Posteriormente, viu-se que o diálogo competitivo, nova modalidade licitatória oriunda do projeto da nova lei de licitações, em um plano teórico, trará grande contribuição para o sistema 
licitatório brasileiro, notadamente para a delimitação do objeto da licitação e a consequente vantagem no momento contratação. Isto porque o diálogo tem por fim convocar os agentes econômicos para um debate de ideias acerca das melhores técnicas para serem inseridas no edital futuro, com o intuito de que supram as necessidades da Administração Pública (que não possui conhecimento aprofundado sobre o que deseja contratar e por isso solicita auxílio dos agentes econômicos).

Embora o diálogo competitivo preveja a possibilidade da integração de agentes econômicos e profissionais técnicos (estes tão somente enquanto membros da comissão de licitação) para debater sobre o aperfeiçoamento de determinado objeto necessário ao Poder Público, entendemos que tais participações somente se concretizarão se for acompanhada de remuneração para tais agentes, em razão das obrigações por eles assumidas.

Entendemos que uma das soluções possíveis é que seja permitida, pela nova lei, a participação de qualquer pessoa do povo neste tipo de debate, desde que ela comprove aptidão técnica condizente com o objeto da licitação. Com isso, haveria a efetivação da democracia participativa, sendo que esta seria uma das formas de remediar os atuais clamores da sociedade com relação à descrença com a democracia e com os governantes.

Essa participação democrática, porém, precisa ser fortemente incentivada, pois, corre-se o risco de eventual preceito legal, prevendo a possibilidade do cidadão participar de processos licitatórios, tornar-se letra morta, sem nenhuma repercussão prática na vida da sociedade e da Administração Pública, como já ocorre com diversos outros preceitos que tentam implantar uma Administração Pública dialógica, na qual a participação do cidadão não se restrinja única e exclusivamente a votar nas eleições, atividade relacionada à democracia representativa.

O que se deseja é que, gradativamente, possa-se ir desenvolvendo, no cidadão, o sentimento de pertencimento, para que ele reconheça que os interesses e patrimônio gerenciados pela Administração Pública, ao contrário de ser res nullius, ou seja, coisa sem dono, na verdade, trata-se de coisa pública que pode e deve ser protegida por todos. Nesse sentido, cuidar para que as licitações públicas sejam mais eficientes é um objetivo que deve ser buscado não apenas pelo legislador, ao aprovar um novo ordenamento jurídico, mas por todos os cidadãos em sua prática diária, numa efetiva adoção da democracia participativa.

\section{REFERÊNCIAS}

ARENDT, Hannah. A condição humana. 8. ed. São Paulo: Companhia das Letras, 1998.

BLACHA, Luis Ernesto. La influencia de las elites para caracterizar a las clases gobernantes. Revista Escuela de Historia, República Argentina, p. 1-22, out. 2016. Disponível em: https:// ri.conicet.gov.ar/handle/11336/116306. Acesso em: 10 jul. 2019. 
BOHMAN, James. La madurez de la democracia deliberativa. Revista Co-herencia, Medellín, v. 13, n. 24, p. 105-143, 2016. doi: 10.17230/co-herencia.13.24.5. Disponível em: http://www. scielo.org.co/pdf/cohe/v13n24/v13n24a05.pdf. Acesso em: 14 jun. 2019.

BRASIL. [Constituição (1988)]. Constituição da República Federativa do Brasil. Brasília, DF: Presidência da República, 1988. Disponível em: http://www.planalto.gov.br/ccivil_03/ constituicao/constituicao.htm. Acesso em: 20 jun. 2019.

BRASIL. Câmara dos Deputados. Projeto de Lei no 1.292/1995. Estabelece normas gerais de licitação e contratação para as administrações públicas diretas, autárquicas e fundacionais da União, Estados, Distrito Federal e Municípios e revoga a Lei n. ${ }^{\circ} 8.666$, de 21 de junho de 1993, a Lei n. ${ }^{\circ} 10.520$, de 17 de julho de 2002, e dispositivos da Lei n. ${ }^{\circ} 12.462$, de 4 de agosto de 2011. Brasília, DF: Câmara dos Deputados, 1995. Disponível em: https://www.camara.leg.br/ proposicoesWeb/fichadetramitacao?idProposicao=16526. Acesso em: 2 jul. 2019.

BRAZ, Petrônio. Tratado de direito municipal: poder legislativo municipal. São Paulo: Mundo Jurídico, 2009. v. 4.

CUNNINGHAM, Frank. Teorias da democracia: uma introdução crítica. São Paulo: Artmed, 2009.

DEVIDES, José Eduardo Costa; DIAS, Jefferson Aparecido. A crise econômica do Brasil e o desenvolvimento sob a ótica de Amartya Sen. Revista Direito e Desenvolvimento, João Pessoa, v. 9, n. 1, p. 213-222, jan./jul. 2018. Disponível em: https://periodicos.unipe.br/index.php/ direitoedesenvolvimento/article/view/572/511. Acesso em: 17 jul. 2019.

FLENIK, Marilucia. As mazelas da democracia e o poder dos cidadãos para recriar a res pública. In: ENCONTRO NACIONAL DO CONPEDI, 27., 2018, Salvador. Anais [...]. Salvador: CONPEDI, 2018. p. 284-303. Disponível em: http://conpedi.danilolr.info/ publicacoes/0ds65m46/1186f849/029MGi7yW24Ym2Qr.pdf. Acesso em: 6 jun. de 2019.

GIDDENS, Anthony. Mundo em descontrole: o que a globalização está fazendo de nós. Tradução de Maria Luiza X. de A. Borges. 3. ed. Rio de Janeiro: Editora Record, 2003.

PAULO VI, Papa. Carta encíclica populorum progressio: sobre o desenvolvimento dos povos. Roma: Libreria Editrice Vaticana, 1967. Disponível em: http://www.vatican.va/content/paul-vi/ pt/encyclicals/documents/hf_p-vi_enc_26031967_populorum.html Acesso em: 19 jul. 2019.

LACERDA, Alan Daniel Freire; MONTEIRO, Lorena Madruga; MOURA, Joana Tereza Vaz de. Teorias da democracia e a práxis política e social brasileira: limites e possibilidades. Sociologias, Porto Alegre, ano 17, n. 38, p. 156-191, jan./abr. 2015. Disponível em: http://www.scielo.br/pdf/ soc/v17n38/1517-4522-soc-17-38-00156.pdf. Acesso em: 7 jul. 2019.

MACHADO, Clara; TOMAZ, Carlos Alberto Simões. As regras do jogo e o jogo das regras: entre a ordem pessoal (autonomia da vontade) e a ordem institucional (espaço público) nas democracias contemporâneas. Revista Argumentum, Marília, v. 19, n. 2, p. 449-464, maio/ago. 2018. Disponível em: http://ojs.unimar.br/index.php/revistaargumentum/article/view/564/287. Acesso em: 26 jun. 2019.

MEIRELLES, Hely Lopes. Direito administrativo brasileiro. 35. ed. São Paulo: Malheiros, 
2009.

MIGUEL, Luis Felipe. Resgatar a participação: democracia participativa e representação política no debate contemporâneo. Lua Nova, São Paulo, v. 100, p. 83-118, 2017. doi: 10.1590/ 0102083118/100. Disponível em: http://www.scielo.br/pdf/ln/n100/1807-0175-ln-100-00083.pdf. Acesso em: 20 jun. 2019.

OLIVEIRA, Rafael Sérgio Lima. O diálogo competitivo do projeto de lei de licitação e contrato brasileiro. 2018. Disponível em: http://licitacaoecontrato.com.br/assets/artigos/artigo_ download_2.pdf. Acesso em: 3 jul. 2019.

ORGANIZAÇÃO DAS NAÇÕES UNIDAS. Assembleia Geral. Declaration on the Right to Development. Adopted by General Assembly resolution 41/128 of 4 december 1986. Disponível em: http://www.un.org/documents/ga/res/41/a41r128.htm. Acesso em: 18 jul. 2019.

PATEMAN, Carole. Participação e teoria democrática. Tradução de Luiz Paulo Rouanet. Rio de Janeiro: Editora Paz e Terra, 1992.

ROCHA, Cármen Lúcia Antunes. O constitucionalismo contemporâneo e a instrumentalização para a eficácia dos direitos fundamentais. Revista do Centro de Estudos Jurídicos da Justiça Federal, Brasília, v. 1, n. 3, set./dez. 1997.

RUE, Letícia Almeida de La; SILVA, Rosane Leal da. O acesso à informação pública por meio de portais como instrumento para a democratização do Poder Judiciário: análise comparativa nos países do Mercosul. 2014. Disponível em: http://www.publicadireito.com.br/ artigos/?cod=3556a3018cce3076. Acesso em: 4 jun. 2019.

SEN, Amartya. Desenvolvimento como liberdade. São Paulo: Companhia das Letras, 2010.

SILVA, José Afonso da. Curso de direito constitucional positivo. 37. ed. São Paulo: Malheiros, 2014.

TAVARES. André Ramos. Direito constitucional econômico. 3. ed. São Paulo: Editora Método, 2011.

Como citar: DEVIDES, José Eduardo Costa; DIAS, Jefferson Aparecido; FERRER, Walkiria Martinez Heinrich. O desafio do projeto da nova lei de licitações com vistas à democracia participativa: o diálogo competitivo. Scientia Iuris, Londrina, v. 25, n. 1, p. 128-143, mar. 2021. DOI: $10.5433 / 21788189.2021 v 25 n 1 p 128$. ISSN: 2178-8189.

Recebido em 17/09/2019

Aprovado em 03/07/2020 